\title{
Attenuating depression behavior by centella asiatica extract \& venlafaxine in mice induced through forced swim and tail suspension test
}

\author{
Aakanksha ${ }^{1}$, Vinay Kumar², Bhulan Kumar Singh², K. Nagarajan ${ }^{3}$, Lalit Machawal ${ }^{4}$, UK Bajaj ${ }^{5}$ \\ ${ }^{1}$ Research Scholar, Deptt. of Pharmacology, Kiet School of Pharmacy, Ghaziabad, (Up)-201206, India \\ ${ }^{2}$ Deptt. of Pharmacology, Kiet School of Pharmacy, Ghaziabad, (Up)-201206, India \\ ${ }^{3}$ Professor \& Head, Deptt. of Pharm. Chemistry, Kiet School of Pharmacy, Ghaziabad, (Up)-201206, India \\ ${ }^{4}$ Department of Pharmacology, University Institute of Pharmaceutical Science, Panjab University, Chandigarh, India \\ ${ }^{5}$ Deptt. of Pharmacology, Kiet School of Pharmacy, Ghaziabad, (Up)-201206, India \\ *Corresponding author E-mail: vinaykumarpatel@gmail.com
}

\begin{abstract}
The present research work was planned to study the combination therapy of Centella asiatica and venlafaxine for antidepressant activity. Wistar albino mice of body weight 25-35g were used in the experiment. Depression was induced by Forced swim test (FST) and Tail suspension test (TST). Immobility, swimming and climbing time and locomotor activity were measured in FST and immobility time was measured in TST. Animals treated with venlafaxine $(10 \mathrm{mg} / \mathrm{kg}) \&$ Centella asiatica $(100 \mathrm{mg} / \mathrm{kg}, 200 \mathrm{mg} / \mathrm{kg}) \&$ combination therapy \{venlafaxine $(10 \mathrm{mg} / \mathrm{kg})+\mathrm{Centella}$ asiatica $(200 \mathrm{mg} / \mathrm{kg})\}$ showed amelioration in swimming time and climbing time while immobility time was attenuated as compared to depression control group. Centella asiatica showed attenuation in immobility time in FST and TST. The finding of the present investigation reveals that combination of venlafaxine and had significant antidepressant effect then alone. In conclusion, Centella asiatica could be used along with venlafaxine because of their neuroprotective effect in depression.
\end{abstract}

Keywords: Antioxidant, centella asiatica, depression, FST, TST, venlafaxine.

\section{Introduction}

Depression is a mental disorder, defined as 'depressed mood on a daily basis for a minimum duration of 2 weeks'. An episode may be characterized by sadness, apathy, changes in sleep pattern, impaired concentration and feeling of shame or guilt, thoughts of dying or death. Approximately, $15 \%$ of the population experiences a major depressive episode at some point in life [1]. At its worst, it can lead to suicide, a tragic fatality associated with the loss of about 850,000 lives every year globally [2]. In India the prevalence of depression is 31.2 per 1000 population [3].

Forced swim test (FST) and tail suspension test (TST) are well established and accepted animal model for depression research. When animals are exposed to the FST and TST they typically adopt an immobile posture, which is thought to reflect a state of behavioral despair or helplessness [4] [5]. Both the animal models are used to induce depression in animals. There are numerous studies indicating that ROS induced neuronal damage which plays crucial role in the pathphysiology of depression, probably by modification to proteins and lipids, damage to DNA, impairment in expression of genes, cellular degeneration and ultimately apoptosis in neurons. There are various antioxidant mechanisms in the brain that neutralize the harmful effects of ROS, however with depression, the loss of efficiency of antioxidants mechanisms [6].

Venlafaxine (VEN) is a novel antidepressant that is both a serotonin and a norepinephrine reuptake inhibitor. Its purported advantage over earlier antidepressants is that it achieves clinical efficacy (mood elevation) more rapidly than the older drugs, an effect that may be attributable to its action on two receptor systems. Venlafaxine had dual effect with serotonin and noradrenaline reuptake inhibitor with a weak effect on dopamine reuptake [7].

Centella asiatica, is a small, herbaceous, annual plant of the family Apiaceae. All parts of the plant are medicinally active including roots. Recent clinical trials have shown that an extract of Centella asiatica is useful for treating leprosy and other skin diseases. It has been valued as a tonic and is used in depression, anxiety, CVS and diabetes [8]. 
Centella asiatica has various CNS activities.

It is important to explore the potential of natural compounds and their combination for treatment of depressive illness. Therefore present study designed with an aim to investigate the effect of Centella asiatica and Venlafaxine on TST and FST induced depression like behavior deficits in mice.

\section{Materials \& methods}

\subsection{Animals}

Swiss albino mice weighing between 25-35 g of either sex were used in the study. The animals were housed under standard laboratory conditions. The study was approved by the Committee for the Purpose of Control and Supervision of Experimental Animals (CPCSEA) of KIET School of Pharmacy, Ghaziabad (UP) (Registration number \& date of registration: 1099/c/07/CPCSEA, dated 27.07.2009).

\subsection{Drugs and treatment}

Venlafaxine (10 mg/kg/p.o.) and Centella asiatica (100, $200 \mathrm{mg} / \mathrm{kg} / \mathrm{p} .0$.) were used in the present study and administered orally daily once a day for 14 days. Centella asiatica extract was obtained as a gift sample from Sanath Products Limited, New Delhi, India.

\subsection{Treatment protocol}

In present study two experimental animal model of depression were used forced swim and tail suspension for both experimental animal model different set of animals was used. In first set the mice were randomly divided into five experimental groups with 6 in each. Group 1 was Depression control, depression induced by forced swim test for 6 min daily for 14 days; Group 2 Depression + Venlafaxine $(10 \mathrm{mg} / \mathrm{kg} / \mathrm{p}$. .o. $)$ for 14 days; Group 3 Depression + Centella asiatica (100 mg/kg/p.o.) for 14 days; Group 4 Depression + Centella asiatica (200 mg/kg/p.o) for 14 days; Group 5 Depression + Venlafaxine (10 mg/kg/p.o)+ Centella asiatica $(200 \mathrm{mg} / \mathrm{kg} / \mathrm{p} .0)$ for 14 days. In second set mice were randomly divided into five experimental groups with 6 in each. Group 1 was Depression control, depression induced by tail suspension test for 6 min daily for 14 days; Group 2 Depression + Venlafaxine (10 mg/kg/p.o.) for 14 days; Group 3 Depression + Centella asiatica (100 mg/kg/p.o.) for 14 days; Group 4 Depression + Centella asiatica (200 mg/kg/p.o) for 14 days; Group 5 Depression + Venlafaxine $(10 \mathrm{mg} / \mathrm{kg} / \mathrm{p} . \mathrm{o})+$ Centella asiatica $(200 \mathrm{mg} / \mathrm{kg} / \mathrm{p} .0)$ for 14 days.

\subsection{Forced swim model}

Mice were individually forced to swim inside a vertical cylinder (height: $25 \mathrm{~cm}$, diameter: $12 \mathrm{~cm}$, containing $15 \mathrm{~cm}$ of water maintained at room temperature). Mice placed in the cylinder and its behavior like swimming time, climbing time and immobility time were recorded. After $6 \mathrm{~min}$ mice taken out, dried by a towel or tissue paper. The water was changed after each test as urination and fecal matter of the former animal may affect the parameters under observation of the latter animal [9].

\subsection{Tail suspension model}

Mice were suspended by the tail with tape from the strain gauge and position of mice was maintained such that the base of their tail is aligned with the bottom of the bar. Each mouse is given 1 trial that last 6 minutes. The total duration of immobility is calculated as the time the force of the mouse's movements is according to preset threshold. Mouse that climbs its tail gently pulled back down and trial was continued and mice that climb their tails for more than $20 \%$ of the trial (i.e. 72 seconds) were eliminated from the final study [9].

\subsection{Locomotor activity}

Assessment of gross motor activity (locomotor activity) was assessed by using actophotometer (IMCORP, Ambala, India). Animals were placed individually in the activity chamber for $3 \mathrm{~min}$ as a habituation period before actual recording of motor activity for next $5 \mathrm{~min}$. Total activity was expressed as counts per $5 \mathrm{~min}$ [10]. 


\subsection{Biochemical estimations}

\subsubsection{Measurement of lipid peroxidation}

The quantitative measurement of lipid peroxidation in the whole brain was measured according to the method of Ohkawa et al. [11]. The amount of malondialdehyde formed was measured by the reaction with thiobarbituric acid at 532nm using Perkin Elmer lambda 20 spectrophotometer. The results were expressed as nano mole of malondialdehyde per milligram protein using the molar extinction coefficient of chromophore $(1.56 \times 10 \mathrm{M}-1 \mathrm{~cm}-1)$.

\subsubsection{Catalase estimation}

Catalase activity was assayed by the method of Claiborne [12], wherein the breakdown of hydrogen peroxides (H2O2) is measured at $240 \mathrm{~nm}$. Briefly, assay mixture consisted of $3 \mathrm{ml}$ of H2O phosphate buffer and $0.05 \mathrm{ml}$ of supernatant of tissue homogenate $(10 \%)$, and change in absorbance was recorded at $240 \mathrm{~nm}$. The results were expressed as micromole $\mathrm{H} 2 \mathrm{O} 2$ decomposed per milligram of protein/min.

\subsubsection{Glutathione estimation}

Reduced glutathione (GSH) in striatum was estimated according to the method described by Ellman [13].

\subsubsection{Superoxide dismutase activity (SOD)}

Superoxide dismutase activity was assayed according to the method of Kono [14] wherein the reduction of nitrazobluetetrazolium (NBT) was inhibited by the superoxide dismutase, is measured at $560 \mathrm{~nm}$ using spectrophotometer (UV-Pharmaspec 1700 Shimadzu, Japan). Briefly, the reaction was initiated by the addition of the hydroxylamine hydrochloride to the mixture containing NBT and sample. The results were expressed as unit/mg Protein.

\subsubsection{Statistical analysis}

The results were expressed as the mean \pm standard error of means (SEM). The results were analyzed using one-way ANOVA followed by post-hoc analysis using Tukey's Multiple Comparison Test. The p value $<0.05$ was considered to be statistically significant

\section{Results}

\subsection{Preliminary photochemical screening}

Preliminary phytochemical screening of extract was confirmed the presence of alkaloids Flavonoids, glycosides, triterpenes, tennins, proteins \& amino acids, volatile \& fatty acids in Centella asiatica extract.

\subsection{Effect of treatment on swimming time}

In the present study, Centella asiatica $(200 \mathrm{mg} / \mathrm{kg})$, venlafaxine $(10 \mathrm{mg} / \mathrm{kg})$ showed significant improved swimming time and attenuated depression behaviour as compared to depression control group. However, combination therapy of venlafaxine $(10 \mathrm{mg} / \mathrm{kg})$, Centella asiatica $(200 \mathrm{mg} / \mathrm{kg})$ treatment showed significant improved swimming time as compared to depression control group, Centella asiatica $(200 \mathrm{mg} / \mathrm{kg})$ and venlafaxine $(10 \mathrm{mg} / \mathrm{kg})$. While there was no significant change in the swimming time in Centella asiatica $(100 \mathrm{mg} / \mathrm{kg}$ ) as compared to depression control group (Fig. $1)$.

\subsection{Effect of treatment on treatment climbing time}

In the present study, Centella asiatica $(200 \mathrm{mg} / \mathrm{kg})$, venlafaxine $(10 \mathrm{mg} / \mathrm{kg})$ showed significant improved climbing time and attenuated depression behaviour as compared to depression control group. However, combination therapy of venlafaxine $(10 \mathrm{mg} / \mathrm{kg})$, Centella asiatica $(200 \mathrm{mg} / \mathrm{kg})$ treatment showed significant improved climbing time as compared to depression control group, Centella asiatica $(200 \mathrm{mg} / \mathrm{kg})$ and venlafaxine $(10 \mathrm{mg} / \mathrm{kg})$. While there was no 
significant change in the climbing time in Centella asiatica $(100 \mathrm{mg} / \mathrm{kg}$ ) as compared to depression control group (Fig. $1)$.

\subsection{Effect of treatment on treatment immobility time}

In the present study, Centella asiatica $(200 \mathrm{mg} / \mathrm{kg})$, venlafaxine $(10 \mathrm{mg} / \mathrm{kg})$ treatment showed significant decrease in immobility time as compared to depression control group. Combination therapy of venlafaxine $(10 \mathrm{mg} / \mathrm{kg})$ and Centella asiatica $(200 \mathrm{mg} / \mathrm{kg}$ ) treatment showed significant decrease in immobility time as compared to depression control group Centella asiatica $(200 \mathrm{mg} / \mathrm{kg})$ and venlafaxine $(10 \mathrm{mg} / \mathrm{kg})$. While there was no significant change in the immobility time in Centella asiatica $(100 \mathrm{mg} / \mathrm{kg})$ as compared to depression control group (Fig. 1).

\subsection{Effect of treatment on locomotor activity}

In the present study, Centella asiatica $(200 \mathrm{mg} / \mathrm{kg})$, venlafaxine $(10 \mathrm{mg} / \mathrm{kg})$ showed significant improved locomotor activity and attenuated depression behaviour as compared to depression control group. However, combination therapy of venlafaxine $(10 \mathrm{mg} / \mathrm{kg})$, Centella asiatica $(200 \mathrm{mg} / \mathrm{kg})$ treatment showed significant improved locomotor activity as compared to depression control group, Centella asiatica $(200 \mathrm{mg} / \mathrm{kg})$ and venlafaxine $(10 \mathrm{mg} / \mathrm{kg})$. While there was no significant change in the locomotor activity in Centella asiatica $(100 \mathrm{mg} / \mathrm{kg})$ as compared to depression control group (Fig. 2).

\subsection{Effect of treatment on immobility time in tail suspension test}

Centella asiatica $(200 \mathrm{mg} / \mathrm{kg})$, venlafaxine $(10 \mathrm{mg} / \mathrm{kg})$ treatment showed significant decrease in immobility time as compared to depression control group. Combination therapy of venlafaxine $(10 \mathrm{mg} / \mathrm{kg})$ and Centella asiatica $(200 \mathrm{mg} / \mathrm{kg})$ treatment showed significant decrease in immobility time as compared to depression control group Centella asiatica $(200 \mathrm{mg} / \mathrm{kg})$ and venlafaxine $(10 \mathrm{mg} / \mathrm{kg})$. While there was no significant change in the immobility time in Centella asiatica $(100 \mathrm{mg} / \mathrm{kg}$ ) as compared to depression control group (Fig. 3).

\subsection{Effect of treatment on oxidative stress in brain}

In the present study, Centella asiatica $(200 \mathrm{mg} / \mathrm{kg})$, venlafaxine $(10 \mathrm{mg} / \mathrm{kg})$ treatment attenuated elevated lipid peroxidation, and restored reduced glutathione, superoxide dismutase and catalase activity as compared to the depression control group. Combination therapy of venlafaxine $(10 \mathrm{mg} / \mathrm{kg})$ and Centella asiatica $(200 \mathrm{mg} / \mathrm{kg})$ treatment showed significant attenuated elevated lipid peroxidation, and restored reduced glutathione, superoxide dismutase and catalase activity as compared to the depression control group. While there was no significant change in the immobility time in Centella asiatica $(100 \mathrm{mg} / \mathrm{kg}$ ) as compared to depression control group (Table. 1).

\section{Discussion}

Depression is a widespread mood disorder that affects an individual's life disturbing his mood, thoughts, thinking, behavior, feelings etc. [15]. The management of depression goes beyond mood improvement in the modern era. Clinically now it was very well documented that patients on depression treatment are coexist with medical complication such as hypertension, diabetes, heart disease, metabolic disorder and cancer [16]. Therefore the current treatment brings us on the question to explore new potential natural compounds for better therapeutic strategy for depression disorder. Depression has been known to cause significantly behaviour, biochemical (oxidative stress, hormone) and cellular deficits (neuroinflammatory mediators, mitochondrial dysfunction) in both experimental as well as clinical setup [17]. Supporting the above, FST and TST test, cause significantly behaviour alteration. The immobility time of the animal is ascertained and a drug having anti-depressant like effect decreases the immobility time. This immobility, referred to as behavioral despair in animals, is claimed to reproduce a condition similar to human depression [18]. Numerous studies have demonstrated that antidepressant drugs such as Venlafaxine, Thioxetine \& Imipramine stimulated the action of serotonin and act by inhibiting the reuptake of biogenic amines in CNS. These drugs were widely used as antidepressant drugs and agreed with studies in animal models, such as forced swimming test [19]. In the present study, the treatment with Centella asiatica, Venlafaxine \& combination therapy i.e. showed significant anti-depressant effect.

In the present study, Centella asiatica, Venlafaxine \& combination therapy treatment significantly improved locomotor activity, in FST and TST induced depression like behaviour. FST and TST were significantly attenuated the locomotor activity [20]. 
In the present study, Centella asiatica, Venlafaxine \& combination therapy treatment significantly improved oxidative stress (restoration of depleted glutathione, catalase activity as well as attenuation of elevated levels of lipid peroxidation and nitrite concentration) suggesting its therapeutic potential against FST and TST induced depression disorder and oxidative damage. Centella asiatica antioxidant like properties has been documented [21] besides oxidative stress contributes significantly in depression like behaviour [22]. This further suggests that Centella asiatica antioxidant like effect might have contributed in reduction of depression like behaviour. However, the exact mechanism is far from elucidation.

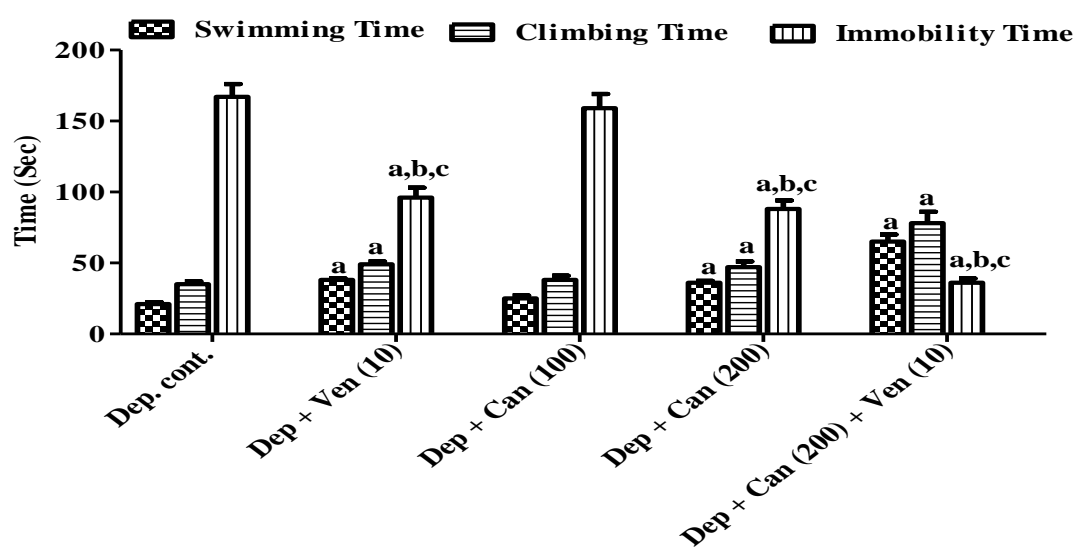

Fig.1: Effect of centella asiatica, venlafaxine and their combination on forced swim test

Values are expressed mean \pm s.e.m. (\% of depression control) (anova followed by tukey test).a $\mathrm{p}<0.05$ as compared to depression control, b $\mathrm{p}<0.05$ as compared to venlafaxine (10), c p<0.05 as compared to centella asiatica (200), dep. cont- depression control, can (100)- centella asiatica(100mg/kg)

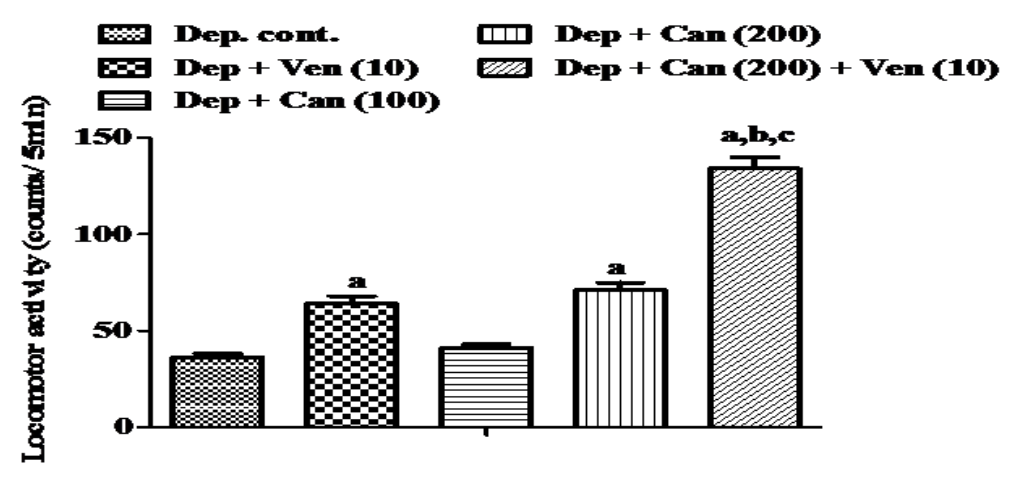

Treatment Groups

Fig.2: Effect of centella asiatica, venlafaxine and their combination on locomotor activity

Values are expressed mean \pm s.e.m. (\% of depression control) (anova followed by tukey test).a $\mathrm{p}<0.05$ as compared to depression control, b $\mathrm{p}<0.05$ as compared to venlafaxine (10), c p $<0.05$ as compared to centella asiatica (200), dep. cont- depression control, can (100)- centella asiatica(100mg/kg)

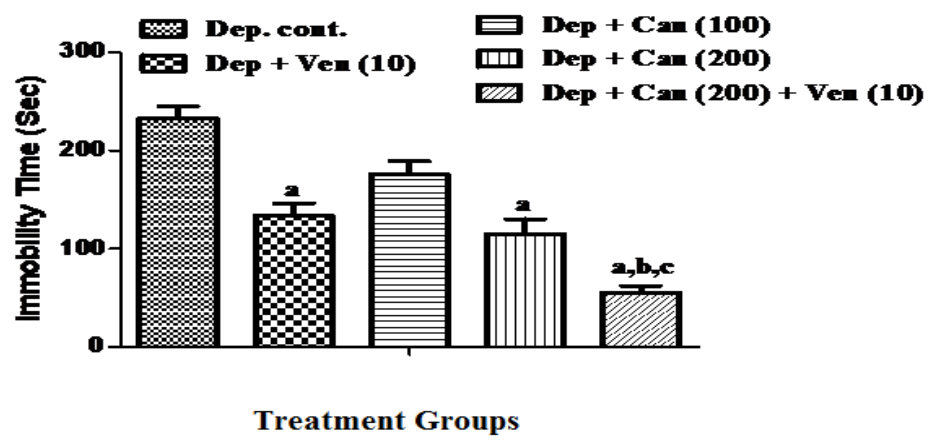

Fig.3: Effect of centella asiatica, venlafaxine and their combination on tail suspension test

Values are expressed mean \pm s.e.m. (\% of depression control) (anova followed by tukey test).a $\mathrm{p}<0.05$ as compared to depression control, $\mathrm{b}$ p $<0.05$ as compared to venlafaxine (10), c p<0.05 as compared to centella asiatica (200), dep. cont- depression control, can (100)- centella asiatica(100mg/kg) 


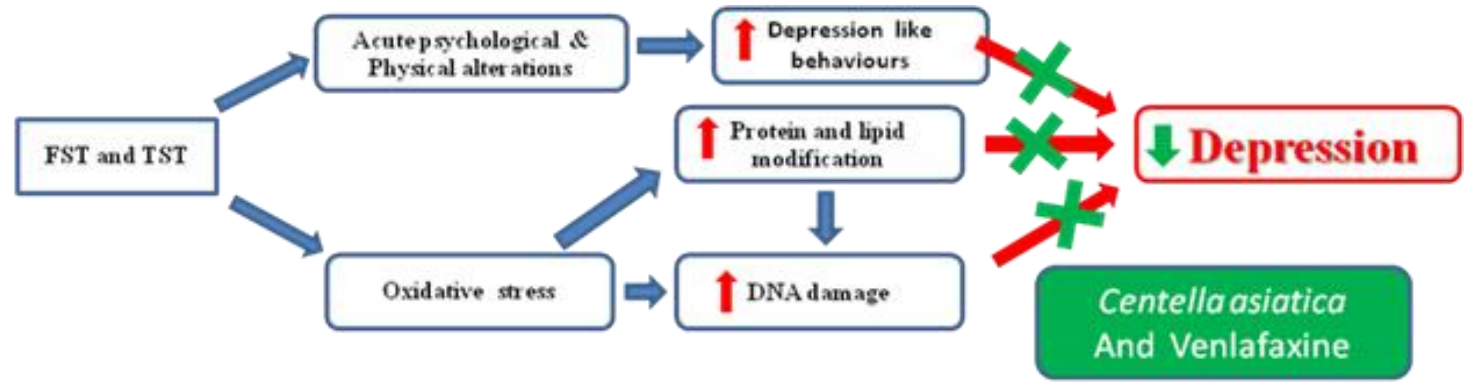

Fig.4: Effect of centella asiatica, venlafaxine and their combination on depression

Table.1: Effect of centella asiatica, venlafaxine and their combination on oxidative stress parameters

\begin{tabular}{|c|c|c|c|c|}
\hline $\begin{array}{l}\text { Treatment group } \\
(\mathrm{mg} / \mathrm{kg})\end{array}$ & $\begin{array}{l}\text { ( } \mathrm{n} \text { mole of MDA/mg } \\
\text { protein) (\% of Naive) }\end{array}$ & $\begin{array}{c}\text { SOD levels } \\
\text { (unit/mg rotein) } \\
\% \text { of sham }\end{array}$ & $\begin{array}{c}\text { Catalase ( } \mu \text { mole of } \\
\left.\mathrm{H}_{2} \mathrm{O} 2 / \mathrm{min} / \mathrm{mg} \text { protein }\right) \\
(\% \text { of Naive })\end{array}$ & $\begin{array}{c}\text { GSH ( } \mu \text { mole of } \\
\text { GSH/mg protein }) \\
(\% \text { of Naive })\end{array}$ \\
\hline Dep. Control. & $\begin{array}{c}5.12 \pm 0.4 \\
(100 \%)\end{array}$ & $\begin{array}{c}0.67 \pm 0.02 \\
(100 \%)\end{array}$ & $\begin{array}{c}1.13 \pm 0.1 \\
(100 \%)\end{array}$ & $\begin{array}{c}0.017 \pm 0.0027 \\
(100 \%)\end{array}$ \\
\hline Dep + Ven (10) & $\begin{array}{l}2.86 \pm 0.19^{\mathrm{a}} \\
\quad(55 \%)\end{array}$ & $\begin{array}{c}1.37 \pm 0.06^{\mathrm{a}} \\
(204 \%)\end{array}$ & $3.14 \pm 0.14^{\mathrm{a}}(277 \%)$ & $\begin{array}{l}0.041 \pm 0.008^{\mathrm{a}} \\
\quad(241 \%)\end{array}$ \\
\hline Dep. + CA (100) & $\begin{array}{c}4.17 \pm .16 \\
(81 \%)\end{array}$ & $\begin{array}{c}0.77 \pm 0.04 \\
(114 \%)\end{array}$ & $1.19 \pm 0.14(105 \%)$ & $\begin{array}{c}0.021 \pm 0.003 \\
(123 \%)\end{array}$ \\
\hline Dep. + Ca(200) & $\begin{array}{c}2.6 \pm .16^{\mathrm{a}} \\
(50 \%)\end{array}$ & $\begin{array}{c}1.31 \pm 0.02^{\mathrm{a}} \\
(168 \%)\end{array}$ & $3.14 \pm 0.16^{\mathrm{a}}(277 \%)$ & $\begin{array}{c}0.037 \pm 0.008^{\mathrm{a}} \\
(370 \%)\end{array}$ \\
\hline Dep.+ CA $(200)+$ Ven (10) & $\begin{array}{c}1.7 \pm 0.13^{\mathrm{a}, \mathrm{b}, \mathrm{c}} \\
(33 \%)\end{array}$ & $\begin{array}{c}2.16 \pm 0.07^{\mathrm{a}, \mathrm{b}, \mathrm{c}} \\
(322 \%)\end{array}$ & $\begin{array}{l}5.7 \pm .16^{\mathrm{a}, \mathrm{b}, \mathrm{c}} \\
(504 \%)\end{array}$ & $\begin{array}{c}0.067 \pm 0.0041^{\mathrm{a}, \mathrm{b}, \mathrm{c}} \\
(394 \%)\end{array}$ \\
\hline
\end{tabular}

as compared to venlafaxine (10), $\mathrm{cP}<0.05$ as compared to Centella asiatica (200), Dep. Cont- Depression control, CA (100) - Centella asiatica $(100 \mathrm{mg} / \mathrm{kg})$

\section{Conclusion}

In conclusion, Centella asiatica treatment significantly attenuated FST and TST induced impaired locomotor activity, depression like behaviour and oxidative stress in brain. The present study further provides a hope that Centella asiatica could be used in the management of depression like problem (Figure 4).

\section{Acknowledgements}

The authors are grateful to Sanath Products Pvt. Ltd. for providing Centella asiatica extract as a gift sample.

\section{References}

[1] A. S. Fauci, E. Braunwald, D. L. Kasper, S. L. Hauser, D. L. Longo, J. L. Jameson, Harrison's principals of internal medicine, 17th ed. McGraw Hill, New York, 2008, 2717-18.

[2] WHO. WHO Director-General unveils new global strategies for mental health. Press Release WHO/99-67, 1999.

[3] S. M. Madhav, Epidemiological study of prevalence of mental disorders in India, Ind. J. Comm. Med. 26 (2001) 198-200.

[4] A. Harkin, T.J. Connor, M.P. Burns, J.P. Kelly, Nitric oxide synthase inhibitors augment the effects of serotonin re-uptake inhibitors in the forced swimming test, European Neuropsychopharmacolology 14 (2004) 274-81.

[5] M. Mantovani, R. Partile, J. B. Calixto, A. R. S. Santos, A.L.S. Rodrigues, Melatonin exerts an antidepressant-like effect in the tail suspension test in mice: evidence for involvement of $\mathrm{N}$-methyl-d-aspartate receptors and the l-arginine-nitric oxide pathway, Neuroscience letters 343 (2003) 1-4.

[6] I. Eren, M. Nazirglu, A. Demirda, O. Celik, A. C. Uguz, A. Altunbasak, Venlafaxine modulates depression-induced oxidative stress in brain and medulla of rat, Neurochemical Research 32 (2007) 497-505.

[7] A.B. Eren, M. Nazirglu, A. Demirda, Protective effects of lamotrigine, aripiprazole and escitalopram on depression-induced oxidative stress in rat brain, Neurochemical research 32 (2007) 1188-1195.

[8] M. Lindner, Chemical Pharmacological and Clinical Profile of The East Asian Medical Plant Centella asiatica, Phytomedicine 7 (2000) $427-$ 48.

[9] H. G. Vogel, Drug Discovery and evaluation pharmacological assay, 3rd ed. Springer publication, New York, 2007, 774-19. 
[10] A. Kumar, R. Garg, A. K. Prakash, Effect of St. John's Wort (Hypericum perforatum) treatment on restraint stress-induced behavioral and biochemical alteration in mice, BMC Complement Altern Med. 10 (2010) 10- 18.

[11] [11] H. Ohkawa, N. Ohishi, Y. Yagi, Assay for lipid peroxides in animal tissue of thiobarbituric acid reaction, Anal. Biochem. 95 (1979) 35158.

[12] A. Claiborne, Catalase activity. In Greenwald RA eds Handbook of methods for oxygen radical research, CRC Press, Boca Raton, 1985, 283284.

[13] G. L.Ellman, Tissue sulfhydryl groups, Archives of Biochemistry and Biophysics 82 (1959) 70-77.

[14] Y. Kono, Concentration of Superoxide radical during autoxidation of hydroxylamine and an assay for superoxide dismutase. Archives of Biochemistry and Biophysics 186 (1978) 189- 195.

[15] D. Dhingra, V. Kumar, Evidences for involvement of monoaminergic and GABAnergic systems in antidepressant like activity of extract of garlic in mice, Indian Journal of Pharmacology 40 (2008) 175-90.

[16] P.P.R. Byrne, K. W. Davidson, R. C. Kessler, G.J.G. Asmundson, Anxiety disorder and comorbid medical illness, General Hospital Psychiatry 30 (2008) 208-225.

[17] S. Moylan, H. A. Eyre, M. Maes, B. T. Baune, F.N. Jacka, M. Berk, Exercising the worry away: How inflammation, oxidative and nitrogen stress mediates the beneficial effect of physical activity on anxiety disorder symptoms and behaviours, Neurosci. Biobehav. Rev. 37 (2013) $573-584$.

[18] I. Tabssum, Z. N. Siddiqui, S. J. Rijvi, Effect of Occimum sanctum and Camellia sinensis on stress-induced anxiety and depression in male albino Rattus norvegicus, Indian Journal of Pharmacology 42 (2010) 283-88.

[19] R. D. Porsalt, G. Anton, N. Blavet, M. Jalfre, Behavioral despair in rats: A new model sensitive to antidepressant treatments, European Journal of Pharmacology 47 (1978) 379-91.

[20] D. Dhingra, A. Sharma, Antidepressant like activity of Glycyrrhiza glabra L. in mouse models of immobility test, Progress in Neuro Psychopharmacology and Biological Psychiatry 30 (2006) 449-454.

[21] H. Nagaraja, P. Kumar, Neuroprotective effect of Centella asiatica extract on experimentally induced Parkinsonism in aged Sprague Dawly rats, The Journal of Toxivological Sciences 35 (2010) 41-47.

[22] O. Erkan, M. Gulec, P. Elif, Antioxidant enzyme activities and oxidative stress, Int. Clin. Psychopharmacol. 19 (2004) $89-95$. 